Journal Club

Editor's Note: These short, critical reviews of recent papers in the Journal, written exclusively by graduate students or postdoctoral fellows, are intended to summarize the important findings of the paper and provide additional insight and commentary. For more information on the format and purpose of the Journal Club, please see http://www.jneurosci.org/misc/ifa_features.shtml.

\title{
Cell-Type-Specific Manipulation Reveals New Specificity in the Neocortical Microcircuit
}

\author{
Alexander Naka \\ Neuroscience Graduate Program, Helen Wills Neuroscience Institute at the University of California, Berkeley, California 94720-3200 \\ Review of Yamawaki and Shepherd
}

The complex connectivity between neurons of the neocortex is governed by rules that give structure to cortical circuits. Most prominently, neurons in different cortical layers form specific axonal projections to various other layers. Patterns of interlaminar connectivity are largely conserved across different neocortical areas, an observation that has led to the idea of a "canonical neocortical microcircuit” (Douglas et al., 1989; Harris and Shepherd, 2015). By shaping the flow of activity within and across cortical layers and columns, the pathways of the canonical microcircuit may represent a basic template for computation in the cortex, which can be adapted to diverse tasks in different cortical regions.

Recently it has been suggested that the cortical wiring diagram should be reconceived as a stereotyped pattern of connectivity between cell types, rather than between layers (Harris and Shepherd, 2015). Among excitatory neurons, cell types can be delineated not only by which layer they occupy, but also by differences in their morphology, intrinsic and functional properties, genetic identity, and

Received April 3, 2015; revised May 8, 2015; accepted May 12, 2015.

I thank Drs. Hillel Adesnik, Alan Mardinly, and Julia Veit for helpful discussion and comments.

The author declares no competing financial interests.

Correspondence should be addressed to Alexander Naka, University of

California, Berkeley, 142 Life Sciences Addition \#3200, Berkeley, CA 94720 -

3200. E-mail: Alex.naka@berkeley.edu.

DOI:10.1523/JNEUROSCI.1297-15.2015

Copyright $\odot 2015$ the authors $\quad 0270-6474 / 15 / 358976-03 \$ 15.00 / 0$ long-range axonal targets. Emerging evidence indicates that they also possess unique patterns of input and output within the local circuit. This organization may endow distinct cell types with specific computational roles; for example, by differentially influencing the activity of different projection neurons, these patterns of connectivity could segregate information into separate output channels. To decipher the logic of the cortical microcircuit, it is therefore critical to determine how its constituent cell types interact functionally.

A recent study by Yamawaki and Shepherd (2015) has done precisely this, in a series of experiments exploiting retrograde labeling techniques to identify and manipulate different types of excitatory cortical projection neurons in layer 5B (L5B) and layer 6 (L6) of murine primary motor cortex (M1). Based on labeling experiments here and in other studies, the authors broadly divide these neurons into three non-overlapping classes: the pyramidal tract (PT) cells of L5B, the corticothalamic (CT) cells of L6, and intratelencephalic (IT) cells, which are found in both layers (Harris and Shepherd, 2015).

To characterize the circuits formed by these cell types, the authors used an approach developed by Shepherd and colleagues in previous work (Apicella et al., 2012; Kiritani et al., 2012), using viral vectors to express channelrhodopsin-2 (ChR2) selectively in only one cell type. By injecting the thalamus, spinal cord, or contralateral cortex/striatum with a modified rabies virus, the authors were able to induce retrograde ChR2 expression in CT,
PT, or IT neurons, respectively, in different experiments. In the same animals, the authors also injected standard retrograde tracers into two of these brain regions. Thus, in acute slice experiments, they could photostimulate a single cell type (e.g., only CT cells) while performing targeted whole-cell recordings of other cell types (e.g., PT cells, IT cells, or nonChR2-expressing CT cells). Photostimulation of each cell type resulted in stereotypical patterns of excitation and inhibition in the other cells types, indicating structured synaptic interactions between cell types (Yamawaki and Shepherd, 2015). Yamawaki and Shepherd (2015) further extended this strategy to investigate how these cell types connect with motor-related thalamic nuclei, completing an elegant and systematic survey of the circuit.

Their approach has several advantages. Targeted optogenetic stimulation allowed the authors to characterize a circuit involving several spatially intermingled groups of cells, which would have been impossible with caged-glutamate-based mapping. Furthermore, because ChR2 is expressed solely by excitatory cells, this technique makes it possible to observe the recruitment of disynaptic inhibition without fear of directly stimulating inhibitory interneurons. However, there are also drawbacks to this method. Most notably, the use of viral vectors results in unavoidable variability in the amount and extent of ChR2 expression between different preparations. In all of their experiments, 
the authors were careful to record from at least two different cell types in each slice and to analyze their results as pairwise comparisons between neurons from the same slice. This is a critical control, which should be standard for this type of experiment.

Using this approach, the authors stimulated specific cell types while measuring the balance of evoked excitation and inhibition (E:I ratio) in neighboring ChR2 neurons. This balance is important to understand because the integration of these two synaptic conductances shapes the rate and timing of spiking output in postsynaptic neurons (Isaacson and Scanziani, 2011). In one experiment, the authors stimulated CT neurons while recording EPSCs and IPSCs in other L6 neurons (both CT and IT). The average amplitude of evoked IPSCs was approximately fivefold greater than that of EPSCs recorded in the same cell (an E:I ratio of $\sim 1: 5$ ). Stimulating IT neurons in similar conditions yielded an E:I ratio of only $\sim 1: 2$. This led them to conclude that the balance of evoked excitation and inhibition is specific to the identity of the stimulated presynaptic population.

E:I balance also differs among postsynaptic cell types. Shepherd and colleagues have previously shown that PT and IT neurons receive dramatically different E:I ratios during stimulation of corticostriatal (IT) neurons using the same methods described above (Kiritani et al., 2012). This has also been seen in sensory cortices: in visual cortex, for example, stimulating CT cells inhibits neurons in layer 4 (L4), but powerfully excites neurons in layer $5 \mathrm{~A}$ (Kim et al., 2014). Furthermore, stimulation of pyramidal cells in layer 2/3 (L2/3) in barrel cortex generates a wide variety of E:I ratios in different cortical layers, which results in a net suppression of other L2/3 cells while simultaneously facilitating spiking in L5 (Adesnik and Scanziani, 2010).

Thus, the E:I balance depends on the identity of both the presynaptic and the postsynaptic cell type, raising the possibility that pathway-specific E:I ratios govern the interactions between cell types in the canonical microcircuit. This degree of specificity would imply that cell types are linked not only by direct monosynaptic connections, but also by indirect yet stereotyped inhibitory circuits.

It is important to note, however, that $\mathrm{E}: \mathrm{I}$ ratios reported in this manner are probably not static features of the cortical circuit. Yamawaki and Shepherd
(2015) conducted their experiments in quiescent slices, and stimulated using brief pulses of wide-field illumination that drove very transient activity (one or a few spikes) in nearly all of the ChR2expressing neurons in the slice. Evoked E:I may be very different when observed in more active conditions or when evoked by a sustained stimulus (Galarreta and Hestrin, 1998; Isaacson and Scanziani, 2011). Further experiments in more naturalistic conditions are needed. Still, measurements of the synaptic response to a brief impulse of activity in a targeted population reflect the direct and indirect connectivity linking cell types. Thus, E:I ratios reported in these types of experiments might be thought of as a predisposition for one cell type to suppress or excite another.

How might stereotyped inhibitory pathways be manifest in the cortical microcircuit? Growing evidence suggests that excitatory cell types can differentially recruit specific populations of interneurons. For example, CT cells in visual cortex appear to preferentially excite certain fast-spiking interneurons (Bortone et al., 2014; Kim et al., 2014), and in L5 of somatosensory cortex, PT neurons, but not IT neurons, can generate disynaptic inhibition by recruiting Martinotti cells (Le Bé et al., 2007). Thus, pathway-specific E:I could be mediated by the activation of specific subsets of interneurons by different excitatory cell types. Inhibitory interneurons could also conceivably target specific classes of excitatory neurons, though the extent to which this occurs in the neocortex is unclear (for review, see Krook-Magnuson et al., 2012; Karnani et al., 2014). Unfortunately, Yamawaki and Shepherd (2015) did not directly record from inhibitory interneurons, though Shepherd's group has previously shown that this approach is effective for characterizing inhibitory circuits (Apicella et al., 2012).

Synaptic mechanisms also likely contribute to pathway-specific E:I ratios. Yamawaki and Shepherd (2015) observed that the E:I ratio generated by stimulation of one cell type was preserved in postsynaptic cells regardless of the absolute magnitude of the evoked synaptic currents, suggesting that excitation and inhibition are matched on a cell-by-cell basis. Recent work in visual cortex uncovered a homeostatic mechanism that maintains E:I in the L4-to-L2/3 pathway by individually scaling the strength of inhibitory synapses onto L2/3 pyramidal cells to match the amount of excitatory input that each individual cell receives from
L4 (Xue et al., 2014). Yamawaki and Shepherd (2015) suggest that a similar mechanism may explain their results. It will be important to determine whether such a mechanism could be extended to multiple pathways with different E:I set points converging on the same cell, or whether other forms and/or loci of plasticity are involved. This could potentially be addressed in the near future using new optogenetic methods to independently control two different cell types in the same preparation (Hooks et al., 2015).

Finally, what can specific E:I ratios tell us about the functionality of different cell types and pathways in the cortical microcircuit? Yamawaki and Shepherd's (2015) findings are largely consistent with a study in visual cortex showing that stimulation of CT cells in visual cortex also evokes a low E:I ratio in other neurons, resulting in a divisive reduction of activity throughout the circuit (Olsen et al., 2012). Thus, these findings suggest that CT cells may act as the "suppression specialists" in the canonical microcircuit in addition to providing feedback to thalamus, which could be tested through similar experiments in other cortical regions. Future experiments in this mold will further refine our map of the cortical microcircuit and improve our understanding of how its form gives rise to its function.

\section{References}

Adesnik H, Scanziani M (2010) Lateral competition for cortical space by layer-specific horizontal circuits. Nature 464:1155-1160. CrossRef Medline

Apicella AJ, Wickersham IR, Seung HS, Shepherd GM (2012) Laminarly orthogonal excitation of fast-spiking and low-threshold-spiking interneurons in mouse motor cortex. J Neurosci 32:7021-7033. CrossRef Medline

Bortone DS, Olsen SR, Scanziani M (2014) Translaminar inhibitory cells recruited by layer 6 corticothalamic neurons suppress visual cortex. Neuron 82:474-485. CrossRef Medline

Douglas RJ, Martin KA, Whitteridge D (1989) Canonical microcircuit for neocortex. Neural Comput 1:480-488. CrossRef

Galarreta M, Hestrin S (1998) Frequencydependent synaptic depression and the balance of excitation and inhibition in the neocortex. Nat Neurosci 1:587-594. CrossRef Medline

Harris KD, Shepherd GM (2015) The neocortical circuit: themes and variations. Nat Neurosci 18:170-181. CrossRef Medline

Hooks BM, Lin JY, Guo C, Svoboda K (2015) Dual-channel circuit mapping reveals sensorimotor convergence in the primary motor cortex. J Neurosci 35:4418-4426. CrossRef Medline 
Isaacson JS, Scanziani M (2011) How inhibition shapes cortical activity. Neuron 72:231-243. CrossRef Medline

Karnani MM, Agetsuma M, Yuste R (2014) A blanket of inhibition: functional inferences from dense inhibitory connectivity. Curr Opin Neurobiol 26:96-102. CrossRef Medline

Kim J, Matney CJ, Blankenship A, Hestrin S, Brown SP (2014) Layer 6 corticothalamic neurons activate a cortical output layer, layer 5a. J Neurosci 34:9656-9664. CrossRef Medline

Kiritani T, Wickersham IR, Seung HS, Shepherd GM (2012) Hierarchical connectivity and connection-specific dynamics in the corticospinal-corticostriatal microcircuit in mouse motor cortex. J Neurosci 32:49925001. CrossRef Medline

Krook-Magnuson E, Varga C, Lee SH, Soltesz I (2012) New dimensions of interneuronal specialization unmasked by principal cell heterogeneity. Trends Neurosci 35:175184. CrossRef Medline

Le Bé JV, Silberberg G, Wang Y, Markram H (2007) Morphological, electrophysiologi$\mathrm{cal}$, and synaptic properties of corticocallosal pyramidal cells in the neonatal rat neocortex. Cereb Cortex 17:2204-2213. CrossRef Medline

Olsen SR, Bortone DS, Adesnik H, Scanziani M (2012) Gain control by layer six in cortical circuits of vision. Nature 483:47-52. CrossRef Medline

Xue M, Atallah BV, Scanziani M (2014) Equalizing excitation-inhibition ratios across visual cortical neurons. Nature 511: 596-600. CrossRef Medline

Yamawaki N, Shepherd GM (2015) Synaptic circuit organization of motor corticothalamic neurons. J Neurosci 35:2293-2307. CrossRef Medline 